\title{
LIXIVIAÇÃO DE FLUMIOXAZIN E METRIBUZIN EM DOIS SOLOS EM CONDIÇÕES DE LABORATÓRIO ${ }^{1,2}$
}

\author{
MAURÍLIO F. DE OLIVEIRA ${ }^{3}$, ANTÔNIO A. DA SILVA ${ }^{4}$, FRANCISCO A. FERREIRA ${ }^{4}$ e HUGO A. RUIZ ${ }^{5}$
}

\section{RESUMO}

Avaliou-se, em condições de casa-devegetação, a mobilidade dos herbicidas flumioxazin e metribuzin nos solos PVc e LVm (coletados em duas regiões diferentes de agricultura no estado de Minas Gerais), em duas condições de umidade (solo seco e úmido). Após aplicação do flumioxazin (60 g/ha) e do metribuzin (384 g/ha) foi feita a simulação de duas lâminas de chuva (45 e $90 \mathrm{~mm})$ sobre colunas contendo os solos nas duas condições. O flumioxazin, aplicado no solo PVc, não foi lixiviado além dos $5 \mathrm{~cm}$ superficiais da coluna; no solo LVm, atingiu os $10 \mathrm{~cm}$ superficiais. O metribuzin apresentou maior mobilidade que o flumioxazin em ambos os solos e condições, chegando atingir uma profundidade de $20 \mathrm{~cm}$ no solo PVc úmido e $45 \mathrm{~cm}$ no solo LVm seco.

Palavras Chave: Adsorção, percolação, tipo de solo.

\section{ABSTRACT \\ Leaching of flumioxazin and metribuzin under greenhouse conditions}

This study was conducted to evaluate leaching of herbicides flumioxazin and metribuzin under greenhouse conditions, in a Utisol and a Oxisol (collected in two differents agricultural regions in the state of Minas Gerais) soils in two moisture conditions (wet and dry soil). Simulation of rainfall $(45 \mathrm{~mm}$ and $90 \mathrm{~mm}$ ) was done after application of flumioxazin $(60 \mathrm{~g} / \mathrm{ha})$ and metribuzin (384 g/ha) in columns containing two soils under wet and dry conditions. Flumioxazin did not leach beyond $5 \mathrm{~cm}$ from the surface when applied in the sandy-loam soil. In the sandy soil, this herbicide reached a depth of $10 \mathrm{~cm}$ from the surface in the column. Metribuzin presented great mobility in both soils and moisture conditions, reaching depth of $20 \mathrm{~cm}$ in wet sandy-loam soil and $45 \mathrm{~cm}$ in dry sandy soil.

Key words: Adsorption, percolation, soil type.

\section{INTRODUÇÃO}

A capacidade de lixiviação de um herbicida depende, entre outros fatores, da sua adsorção pelos colóides do solo, da sua solubilidade em água e da quantidade de chuva após a aplicação (Velini, 1992), sendo diretamente proporcional à precipitação, em determinado período. Nas regiões úmidas, a lixiviação é motivo de preocupação, pois o movimento descendente de alguns herbicidas pode torná-los ineficientes, colocando-os além da zona de germinação das sementes das plantas daninhas e podendo, em casos extremos, até contaminar o lençol freático.

Os herbicidas ionizáveis, com maiores solubilidades em água e menores valores do

\footnotetext{
1 Recebido para publicação em 08/08/96 e na forma revisada em 09/12/97.

2 Parte da dissertação do primeiro autor apresentada à Universidade Federal de Viçosa.

3 Pós-Graduando, MS, Departamento de Fitotecnia/UFV, Viçosa/MG, CEP: 36571-000.

4 Professor do Departamento de Fitotecnia/UFV, Viçosa/MG, CEP: 36571-000.

5 Professor do Departamento de Solos/UFV, Viçosa/MG, CEP: 36571-000.
} 
coeficiente de partição octanol/água $\left(\mathrm{K}_{\mathrm{oa}}\right)$, são também os mais móveis nos solos, indicando uma provável correlação inversa entre a intensidade da adsorção e a solubilidade dos herbicidas, bem como razão direta entre a adsorção e os valores de $\mathrm{K}_{\text {oa }}$ (Graveel \& Turco,1994).

A movimentação do herbicida no perfil do solo ocorre em todas as direções e é dependente da direção do fluxo de água. Devido a ocorrência de grandes volumes de água de percolação nos solos após chuvas pesadas ou irrigações, a direção mais comum na qual os herbicidas são lixiviados é a descendente. A lixiviação interfere no comportamento do herbicida no solo, podendo torná-lo mais ou menos eficiente, influenciando ou não sua seletividade e auxiliando sua remoção da superfície do solo.

O flumioxazin proporciona excelente controle de diversas espécies daninhas dicotiledôneas e algumas monocotiledôneas, invasoras das culturas de soja. Segundo Silva (1993), a aplicação de $60 \mathrm{~g} / \mathrm{ha}$ de flumioxazin em um Latossolo Roxo distrófico promoveu bom controle de Desmodium purpureum, Euphorbia heterophylla, Bidens pilosa e Commmelina benghalensis. Excelente controle das dicotiledôneas citadas e de algumas gramíneas, destacando-se a Brachiaria plantaginea, foi verificado quando se misturou o flumioxazin com os graminicidas alachlor, metolachlor e trifluralin. Este herbicida pertence ao grupo químico das ftalamidas, possuindo ação sobre a rota de síntese da clorofila, especificamente acumulando porfirinas. Apresenta baixa solubilidade em água: 0,6 a $1,2 \mathrm{mg} / \mathrm{L}$ a $20^{\circ} \mathrm{C}$, e pressão de vapor da ordem de $3,0 \times 10^{-7} \mathrm{mmHg}$ a $20^{\circ} \mathrm{C}$ (Sumitomo Chemical Ltda) ${ }^{*}$.

O metribuzin é um herbicida do grupo das triazinas assimétricas que age por inibição da fotossíntese. Seu peso molecular é de 214,3 e possui solubilidade em água de $1.200 \mathrm{mg} / \mathrm{L}$ a $20^{\circ} \mathrm{C}$ (Deuber 1992 e Velini 1992). É um produto de baixa pressão de vapor $\left(<10^{-5} \mathrm{mmHg}\right.$ a $\left.20^{\circ} \mathrm{C}\right)$ não

\footnotetext{
* Informação pessoal do Sr. ISHIZUKA, H., presidente da empresa.
}

apresentando volatilidade nas condições ambientais. É recomendado para o controle de invasoras nas culturas de soja, café, mandioca, aspargo, batata, cana-de-açúcar e tomate, dentre outras (Almeida e Rodrigues, 1988).

A mobilidade do metribuzin foi infuenciada pelos conteúdos de areia, argila e matéria orgânica (Savage, 1976 e Peter \& Weber, 1985), bem como pela umidade do solo (Savage, 1976). Segundo Sharom \& Stephenson (1976), o metribuzin é relativamente móvel em solos minerais e praticamente imóvel em solo orgânico e a mobilidade está inversamente correlacionada com o conteúdo de matéria orgânica do solo. Coble \& Schrader (1973) e Wax (1977) verificaram que a uniformidade, a quantidade e a distribuição de água, após a aplicação do metribuzin, influenciaram o controle de plantas daninhas e tolerância da soja ao herbicida.

Não há informações sobre a mobilidade de flumioxazin nas condições do Brasil.

O presente trabalho teve como objetivo avaliar a lixiviação do flumioxazin e do metribuzin nos solos PVc e LVm, aplicados em solo úmido e seco, decorrente da simulação de duas lâminas de chuva.

\section{MATERIAL E MÉTODOS}

Em experimento conduzido em casa-devegetação, no campus da Universidade Federal de Viçosa - MG, avaliou-se a lixiviação dos herbicidas flumioxazin e metribuzin, em solos Podzólico Vermelho-Amarelo câmbico fase terraço (PVc) e Latossolo Vermelho-Amarelo textura média $(\mathrm{LVm})$, caracterizados física e quimicamente (Tabela 1). As análises foram realizadas nos laboratórios de análises físicas e químicas de solo do Departameto de Solos da UFV, segundo metodologia proposta pela EMBRAPA (1979). Foi utilizado o delineamento experimental inteiramente casualizado, com oito repetições.

Os solos, previamente passados em peneira de $4 \mathrm{~mm}$ e secos ao ar, foram colocados em tubos de PVC rígido com $50 \mathrm{~cm}$ de 
comprimento e diâmetro interno de $0,091 \mathrm{~m}$. Os tubos, previamente preparados, foram seccionados longitudinalmente em 2 regiões diferentes, obtendo-se abertura lateral de $5 \mathrm{~cm}$ a qual foi fixada ao próprio material do tubo, com fita adesiva e discos de borracha. Internamente, para evitar o escorrimento lateral da solução do solo, aplicou-se camada de parafina. $\mathrm{Na}$ parte basal foram colocados gaze hidrófila e papel-filtro, ambos amarrados e fixados por uma placa-dePetri. Após o preparo, os solos foram lentamente colocados nos tubos, buscando evitar possíveis camadas compactadas. A quantidade de solo adicionada nos tubos variou em função do tipo de solo.

TABELA 1. Resultados da análise granulométrica, da umidade residual (Ure), da densidade do solo (Dp), da densidade de partícula (Dr), da porosidade (P) e das análises químicas dos solos Podzólico Vermelho-Amarelo câmbico fase terraço (PVc) e Latossolo Vermelho-Amarelo textura média (LVm).

\begin{tabular}{lcc}
\hline \multicolumn{1}{c}{ Análise granulométrica } & PVc & LVm \\
\hline Areia grossa $(\%)$ & 34 & 28 \\
Areia fina $(\%)$ & 18 & 54 \\
Silte $(\%)$ & 06 & 01 \\
Argila $(\%)$ & 42 & 17 \\
Ure $(\%)$ & 2,77 & 0,40 \\
Dp $\left(\mathrm{g} / \mathrm{cm}^{3}\right)$ & 1,04 & 1,45 \\
Dr $\left(\mathrm{g} / \mathrm{cm}^{3}\right)$ & 2,53 & 2,60 \\
$\mathrm{P}(\%)$ & 58,89 & 44,23 \\
\hline Análises químicas & & \\
\hline Carbono orgânico $(\mathrm{g} / \mathrm{kg})$ & 30,4 & 5,1 \\
pH H $\mathrm{H}_{2} \mathrm{O}(1: 2,5)$ & 5,4 & 5,6 \\
CTC efetiva $\left(\mathrm{cmol}_{\mathrm{c}} / \mathrm{dm}^{3}\right)$ & 6,28 & 2,57 \\
CTC total $\left(\mathrm{cmol}_{\mathrm{d}} / \mathrm{dm}^{3}\right)$ & 11,68 & 4,97 \\
\hline
\end{tabular}

Para se obter a condição de solo úmido (20,6\% e $27,0 \%$ de umidade em base gravimétrica no solo PVc e no solo LVm, respectivamente), foram aplicadas lâminas de chuva de $138 \mathrm{~mm}$ em 120 minutos no solo PVc e $92 \mathrm{~mm}$ em 80 minutos no solo LVm. Para permitir a drenagem do excesso de água esperou -se 24 horas. Durante esse período, para evitar ressecamento superficial, as colunas foram cobertas com filme de polietileno. Após este período, foram feitas as aplicações dos herbicidas flumioxazin (80 $\mathrm{g} / \mathrm{ha})$ e metribuzin (384g/ha) no topo das colunas.

Para aplicação dos herbicidas foi utilizado um pulverizador costal pressurizado com $\mathrm{CO}_{2}$, provido de barra de $0,5 \mathrm{~m}$ contendo dois bicos do tipo leque da série 80.03. A pressão foi de $3,0 \mathrm{kgf} / \mathrm{cm}^{2}$, sendo o pulverizador calibrado para se obter vazão de 200 1/ha.
Passadas 24 horas da aplicação dos herbicidas, as colunas foram submetidas a duas lâminas de chuva: 45 e $90 \mathrm{~mm}$, e deixadas em repouso por mais 24 horas, sendo realizada, durante este período, a coleta do lixiviado.

Em metade das unidades experimentais, as colunas foram abertas, longitudinalmente, e colocadas na posição horizontal, fazendo-se, ao longo da coluna, a semeadura da planta-teste (pepino Caipira 'AG 221', Cucumis sativus L.). Na outra metade, o solo foi coletado a intervalos (profundidades) de $5 \mathrm{~cm}$ e colocado em vasos de $430 \mathrm{~cm}^{3}$, revestidos com sacos de polietileno, semeando-se em seguida 6 sementes da plantateste, a 1,5 $\mathrm{cm}$ de profundidade, em cada vaso.

O lixiviado coletado foi aplicado em vasos contendo areia lavada (material inerte) onde semeou-se a planta indicadora. Neste e nos demais 
vasos foi aplicada, uma vez por semana, solução nutritiva visando adequado desenvolvimento da planta-teste.

O controle de umidade nos vasos e nas colunas foi feito com um medidor de potencial de água no solo (Floral Sensor) da marca INOGON, quatro vezes ao dia. Quando a umidade dos solos atingia um valor mínimo, os vasos eram levados ao simulador de chuvas e irrigados, mantendo-a aproximadamente $80-90 \%$ da capacidade de campo.

As avaliações dos resultados foram realizadas aos 17 dias após a semeadura. Para isto, as colunas na horizontal foram divididas em seções de $5 \mathrm{~cm}$, a partir da superfície onde o herbicida foi aplicado. Em cada seção da coluna avaliou-se a produção de biomassa verde de pepino.

Foi calculada a produção de biomassa média por vaso e por seção (profundidade de semeadura na coluna). Em seguida foi realizada análise de variância, verificando se houve efeito significativo para as lâminas simuladas; para o local de concentração dos herbicidas nas colunas após simulações das lâminas (profundidade de semeadura do pepino ao longo da coluna) e para a interação entre lâmina e profundidade, por solo estudado, sobre a produção de biomassa de pepino. Para a escolha dos modelos foi considerada a significância do teste $\mathrm{F}$, maior coeficiente de determinação $\mathrm{R}^{2} \mathrm{e}$ desvio da regressão não-significativo. Quando a variável profundidade apresentou-se significativa, seus graus de liberdade foram decompostos testando-se modelos até o quinto grau. $\mathrm{O}$ modelo cúbico foi adotado como o de máximo grau de ajuste, para ambos os solos.

\section{RESULTADOS E DISCUSSÃO}

$\mathrm{Na}$ Figura 1, observa-se produção de biomassa de plantas de pepino cultivadas no solo PVc e tratadas com flumioxazin. Em condições de solo seco ao ar e em solo úmido foi observada menor biomassa nos $5 \mathrm{~cm}$ a partir da superfície, independentemente da lâmina de chuva aplicada.
O modelo que melhor explicou o movimento do flumioxazin nesse solo foi o cúbico. Porém, o ajuste não foi bom visto que $\mathrm{o} \mathrm{R}^{2}$ ficou por volta de $66 \%$.

A alta adsorção do herbicida ao solo (Shea 1985; Harper, 1988 e Oliveira, 1995); sua baixa solubilidade em água (Roowell, 1994 e Graveel \& Turco, 1994), a alta percentagem de microporos apresentada no solo PVc (Fontes, 1978) podem explicar a pequena movimentação do herbicida neste solo, até mesmo quando aplicado em solo úmido.

Quando o flumioxazin foi aplicado no LVm seco ao ar, não foi verificado efeito significativo quanto à lâminas. Este efeito demonstra que, não houve diferenças na produção de biomassa de pepino com a simulação da lâmina de $45 \mathrm{~mm}$ e $90 \mathrm{~mm}$, após aplicação do flumioxazin. O modelo que melhor explicou o movimento do flumioxazin neste solo foi o cúbico. $\mathrm{Na}$ Figura 1, verifica-se que ocorreu menor produção de biomassa nos $10 \mathrm{~cm}$ superficiais da coluna, o que evidencia a presença do herbicida nesta profundidade. A menor adsorção do flumioxazin nesse solo (Oliveira, 1995) caracteriza sua maior percolação.

O modelo cúbico foi o que melhor ajustou aos dados, explicando a lixiviação do metribuzin quando o solo PVc se encontrava nas condições de seco ao ar (Figura 2) e úmido (Figura 3). Houve efeito significativo para a profundidade atingida pelo herbicida na coluna, em ambas as condições de umidade $(\mathrm{p}<0,01)$. A interação entre lâmina simulada e profundidade atingida pelo metribuzin também foi significativa, em ambas as condições de umidade do solo $(\mathrm{p}<0,01)$.

Na Figura 2, verifica-se o movimento do metribuzin aplicado no $\mathrm{PVc}$ foi afetado pela lâmina de chuva simulada ( $\mathrm{p}<0,05)$. Ambas as lâminas simuladas no solo $\mathrm{PVc}$ seco ao ar, acarretaram redução na produção de biomassa de pepino nos $15 \mathrm{~cm}$ e $20 \mathrm{~cm}$ superficiais da coluna para 45 e $90 \mathrm{~mm}$ de chuva, respectivamente. Porém, menores valores de biomassa ocorreram após a simulação da lâmina de $90 \mathrm{~mm}$ nos $10 \mathrm{~cm}$ 
superficiais, o que evidencia maior concen tração do herbicida nesta região.

Analisando a Figura 3, verifica-se que quando o solo PVc se encontrava úmido no momento da aplicação do produto, o metribuzin atingiu os $15 \mathrm{~cm}$ superficiais da coluna quando foi simulada lâmina de chuva de $45 \mathrm{~mm}$ após aplicação do herbicida.

Nesta condição, a simulação da lâmina de chuva de $90 \mathrm{~mm}$ acarretou diluição do produto ao longo da coluna. Menor adsorção do produto, devido aos lugares adsortivos do solo estarem ocupados pela água, e a diluição do metribuzin devido sua solubilidade, podem ter contribuído positivamente para maior descida do produto (Savage, 1976). Este forte arraste das moléculas do herbicida quando foi aplicada a lâmina de 90 mm pode ser caracterizado pela maior produção de biomassa nos $10 \mathrm{~cm}$ superficiais da coluna nesta lâmina comparada com a produção de biomassa nesta mesma profundidade, na lâmina de $45 \mathrm{~mm}$. A menor produção de biomassa de pepino na lâmina de $90 \mathrm{~mm}$ em relação à lâmina de $45 \mathrm{~mm}$, a partir dos $10 \mathrm{~cm}$ superficiais, também evidencia o exposto acima.

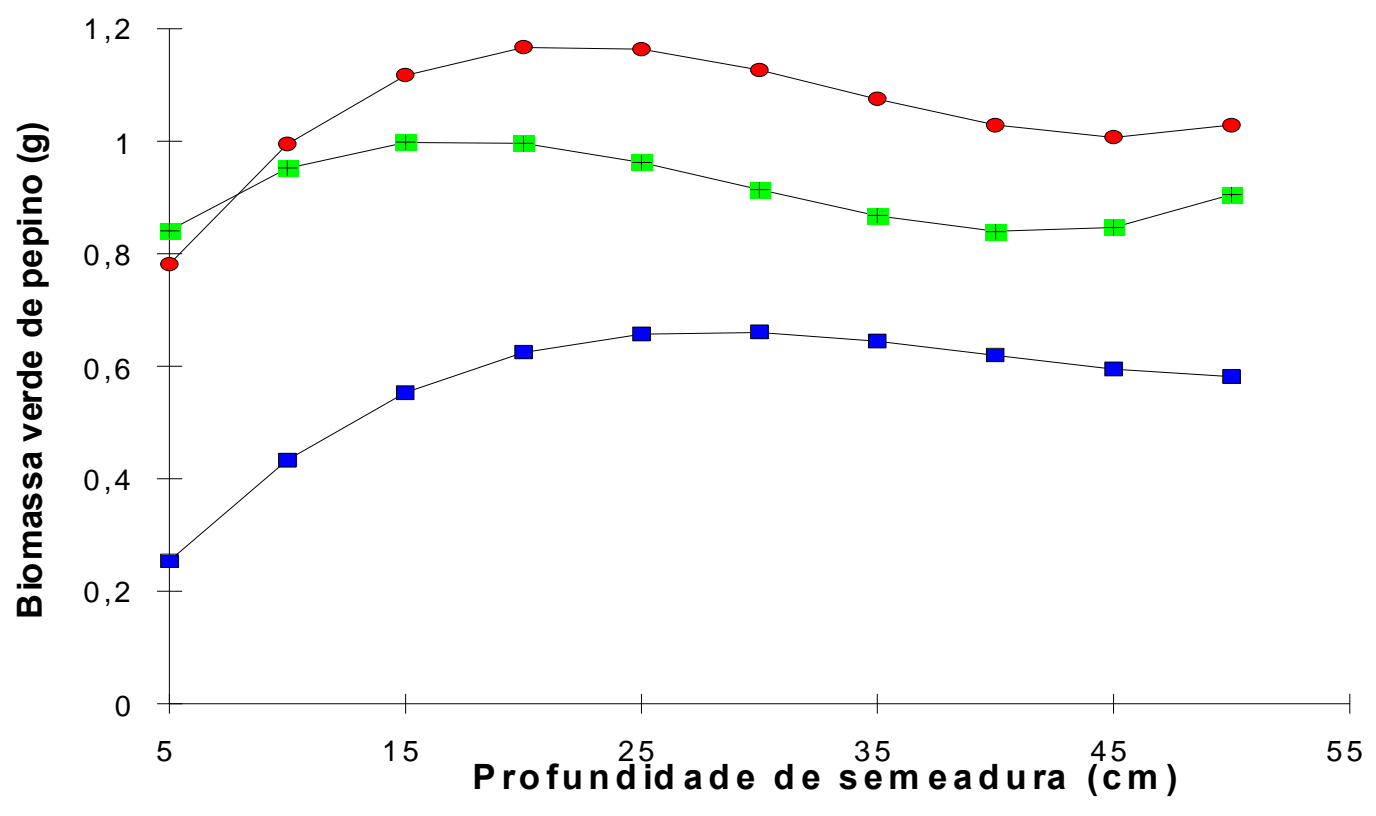

$\mathrm{Y}(\bullet)=0,006393+0,057098 \cdot \mathrm{PR}-0,001573 \cdot \mathrm{PR}^{2}+0,00001322 . \mathrm{PR}^{3} ; \mathrm{R}^{2}=0,66$ $\mathrm{Y}(+)=0,649680+0,047587 \cdot \mathrm{PR}-0,001956 \cdot \mathrm{PR}^{2}+0,00002213 \cdot \mathrm{PR}^{3} ; \mathrm{R}^{2}=0,63$ $\mathrm{Y}(\circ)=0,456407+0,077423 \cdot \mathrm{PR}-0,002611 \cdot \mathrm{PR}^{2}+0,00002583 \cdot \mathrm{PR}^{3} ; \mathrm{R}^{2}=0,66$

FIGURA 1. Efeito das condições dos solos Podzólico Vermelho-Amarelo câmbico (seco ao Ar (०) e solo úmido (+)) e do Latossolo Vermelho-Amarelo textura média (seco ao ar (•)) em diferentes profundidades (PR) sobre a biomassa fresca de pepino, após aplicação de flumioxazin, cultivado em coluna em casa-de-vegetação, em Viçosa - MG, 1994. 


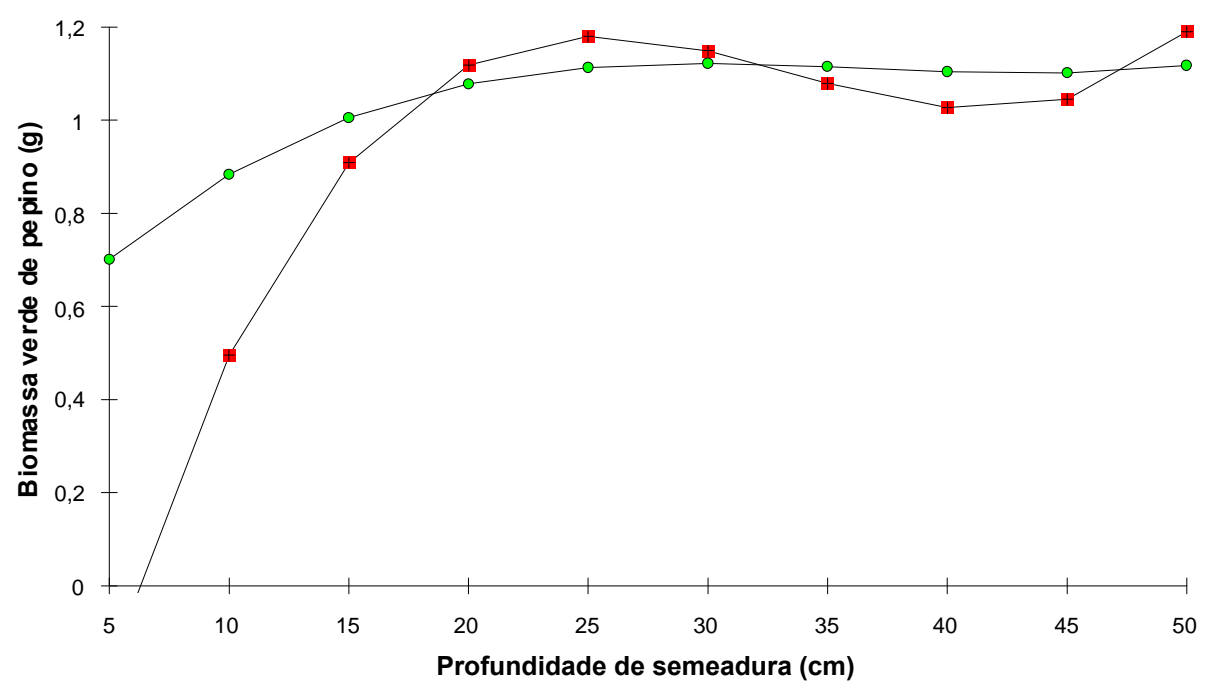

$\mathrm{Y}(+)=-1,157630+0,231504 . \mathrm{PR}-0,007348 . \mathrm{PR}^{2}+0,00007314 . \mathrm{PR}^{3} ; \mathrm{R}^{2}=0,79$ $\mathrm{Y}(\circ)=0,447490+0,058725 \cdot \mathrm{PR}-0,001661 . \mathrm{PR}^{2}+0,00001509 \cdot \mathrm{PR}^{3} ; \mathrm{R}^{2}=0,77$

FIGURA 2. Biomassa verde de plantas de pepino cultivadas no solo Podzólico Vermelho-Amarelo câmbico em colunas, após a aplicação do metribuzin em condições de solo seco ao ar, seguida de lâminas de chuva de 45 (॰) e 90 mm (+). Viçosa - MG, 1994.

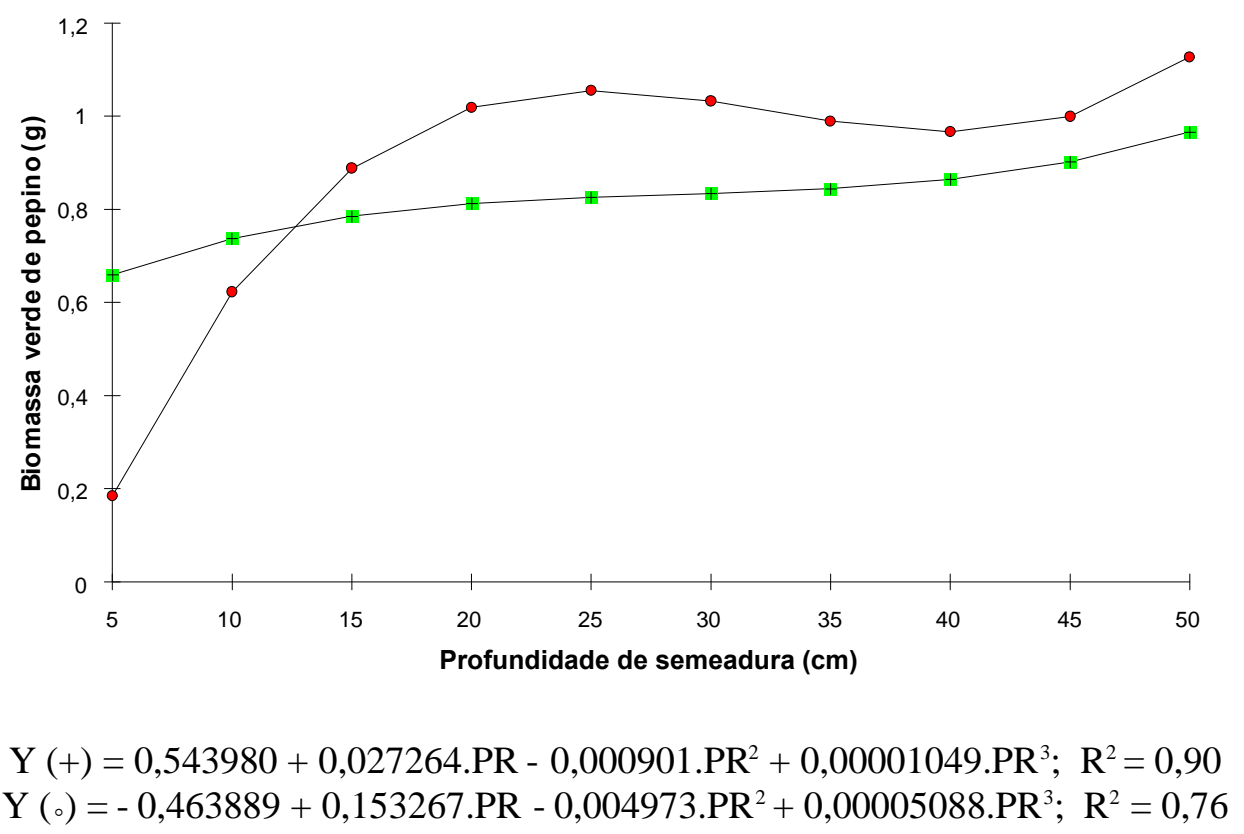

FIGURA 3. Biomassa verde de plantas de pepino cultivadas no solo Podzólico Vermelho-Amarelo câmbico em colunas, após a aplicação do metribuzin em condições de solo úmido, seguida de lâminas de chuva de 45 ( o) e 90 mm (+). Viçosa - MG, 1994. 
A lâmina de chuva aplicada apresentou efeito significativo $(\mathrm{p}<0,01)$ somente quando o solo LVm se encontrava seco, antes da aplicação do metribuzin. Em ambas as condições de umidade deste solo, houve diferenças na produção de biomassa entre as profundidades de semeadura da planta-teste. Este fato evidencia a concentração desuniforme do metribuzin na coluna (Figuras $4 \mathrm{e}$ $5)$.

Nestas figuras, podemos verificar que o modelo cúbico foi o que melhor se ajustou à produção de biomassa das plantas de pepino em função do movimento do metribuzin no LVm.

$\mathrm{Na}$ Figura 4, verificou-se que, quando o produto foi aplicado em solo seco e, em seguida foi simulada chuva de $45 \mathrm{~mm}$, praticamente não houve produção de biomassa de pepino na profundidade de 10 a $20 \mathrm{~cm}$. Porém, quando após a aplicação do produto em solo seco ao ar foi simulada uma chuva de $90 \mathrm{~mm}$, a maior redução na produção de biomassa das plantas de pepino ocorreu na profundidade de $25 \mathrm{a} 45 \mathrm{~cm}$. A simulação de maior lâmina de chuva nesse solo provocou lixiviação do produto para maior profundidade.

Quando o metribuzin foi aplicado em solo úmido (Figura 5), seguido da lâmina de $45 \mathrm{~mm}$, houve novamente maior redução da biomassa fresca das plantas de pepino no intervalo de 10 a $20 \mathrm{~cm}$ de profundidade. No entanto, quando foi aplicada uma lâmina de $90 \mathrm{~mm}$, a menor biomassa fresca ocorreu na profundidade entre 15 e $25 \mathrm{~cm}$, evidenciando que, a lâmina de $90 \mathrm{~mm}$ promoveu arraste do metribuzin para maior profundidade.

Comparando a mobilidade do metribuzin nos dois solos, verificou-se maior lixiviação deste herbicida no LVm do que no PVc. Esse resultado está de acordo com os de Sharom \& Stephenson (1976), Savage (1976) e Peek \& Appleby (1989), os quais demonstraram que a mobilidade do metribuzin no solo é inversamente proporcional à capacidade de adsorção do herbicida aos colóides do solo.

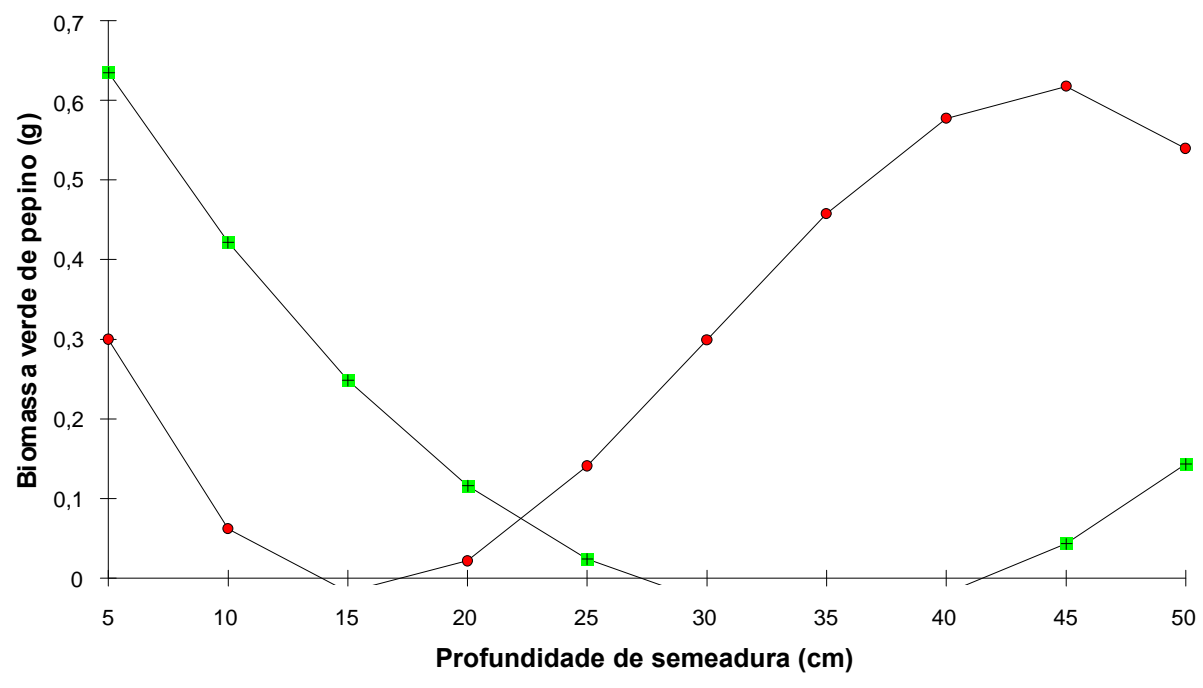

$\mathrm{Y}(+)=0,889411-0,055066 \cdot \mathrm{PR}+0,000833 \cdot \mathrm{PR}^{2}-0,0000005998 \cdot \mathrm{PR}^{3} ; \mathrm{R}^{2}=0,93$

$\mathrm{Y}(\circ)=0,735815-0,109581 \cdot \mathrm{PR}+0,004749 \cdot \mathrm{PR}^{2}-0,00005272 \cdot \mathrm{PR}^{3} ; \mathrm{R}^{2}=0,88$

FIGURA 4. Biomassa verde de plantas de pepino cultivadas no solo Latossolo Vermelho-Amarelo textura média em colunas, após a aplicação do metribuzin em condições de solo seco ao ar, seguida de lâminas de chuva de 45 (०) e 90 mm (+). Viçosa - MG, 1994. 


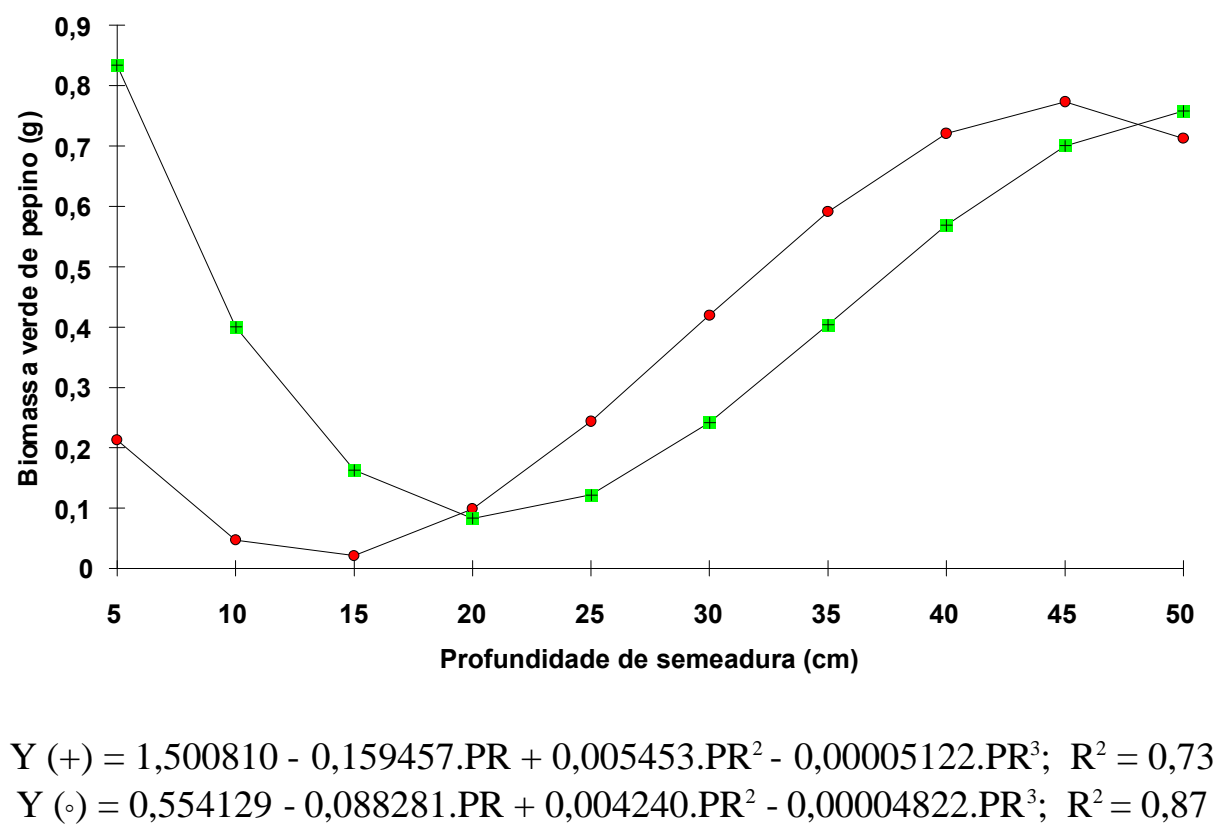

FIGURA 5. Biomassa verde de plantas de pepino cultivadas no solo Latossolo Vermelho Amarelo textura média em colunas, após a aplicação do metribuzin em condições de solo úmido, seguida de lâminas de chuva de 45 (。) e 90 mm (+). Viçosa - MG, 1994.

Uma das possíveis causas da maior percolação do metribuzin em relação à do flumioxazin está no fato do metribuzin apresentar maior solubilidade (Ladlie et al. 1976; Savage, 1976; Peter \& Weber 1985 e Jones et al. 1990). Entretanto, diversos outros fatores, como tamanho e natureza iônica da molécula também podem estar envolvidos.

No entanto, conclui-se que a mobilidade do flumioxazin foi pequena, não ultrapassando os $5 \mathrm{~cm}$ superficiais no solo PVc, independentemente da lâmina simulada após sua aplicação. No solo LVm, o flumioxazin apresentou maior mobilidade que no solo $\mathrm{PVc}$, atingindo os $10 \mathrm{~cm}$ superficiais da coluna.

A lixiviação do metribuzin foi afetada pela condição inicial de umidade do solo e pela lâmina de chuva simulada. $\mathrm{O}$ metribuzin acarretou menor produção de biomassa de pepino nos $15 \mathrm{~cm}$ superficiais da coluna quando foi aplicado no solo PVc seco ar. No solo LVm seco ar, este produto atingiu a profunidade de $45 \mathrm{~cm}$ quando foi simulada chuva de $90 \mathrm{~mm}$.

\section{LITERATURA CITADA}

ALMEIDA, F. S. \& RODRIGUES, B. N. Guia de herbicidas. 2 ed. Londrina, IAPAR, 1988. p. 630 .

COBLE, H. D. \& SCHRADER, J. W. Soybean tolerance to metribuzin. Weed Sci. v. 21, 1973. p. 308-309.

DEUBER, R. Métodos de controle das plantas daninhas. In: Ciências das Plantas Daninhas. Jaboticabal, UNESP, 1992. p. 109-148.

EMPRESA BRASILEIA DE PESQUISA AGROPECUÁRIA - Serviço Nacional de Levantamento e Conservação de Solos. Manual de métodos de análise de solo. Rio de Janeiro, EMBRAPA-SNLCS. 1979. n.p.

FONTES, L. E. F. Movimento e inativação do metribuzin em materiais de dois solos, 
sob diferentes densidades aparentes. Viçosa - MG, Universidade Federal de Viçosa. 1978. 40 p. (Tese de Mestrado).

GRAVEEL, J. G. \& TURCO, R. F. Factors affecting mobility of pesticides in soil. In: Herbicide action. West Lafayette, Purdue University, 1994. 775 p.

HARPER, S. S. Sorption of metribuzin in surface and subsurface soils of the Mississipi Delta region. Weed Sci. v. 36, n.1, p. 84-89, 1988.

JONES, R. E.; BANKS Jr., P.A.; RADCKUFFE, D. E. Alachlor and metribuzin movement and dissipation in a soil profile as influenced by soil surface condition. Weed Sci. v. 38, p. 589-597, 1990.

LADLIE, J. S.; MEGGITT, W. F.; PENNER, D. Effect of soil $\mathrm{pH}$ on microbial degradation, adsorption, and mobility of metribuzin in soil. Weed Sci. v. 24, n.5, p. 477-481, 1976.

OLIVEIRA, M. F. Adsorção, lixiviação e persistência de flumioxazin e metribuzin em diferentes solos. Viçosa - MG, Universidade Federal de Viçosa. 1995. 71 p. (Tese de Mestrado).

PEEK, D. C. \& APPLEBY, A. P. Phytotoxicity, adsorption, and mobility of metribuzin and Its ethylthio analog as influenced by soil proprerties. Weed Sci. v. 37, p. 419-423, 1989.

PETER, C. J. \& WEBER, J. B. Adsorption, mobility and efficacy of metribuzin as influenced by soil properties. Weed Sci. v. 33, p. 868-873, 1985.

ROOWELL, D. L. Pesticides and metals. In: Soil science: methods and applications. London, Longman Scientist Technical, 1994. 350 p.

SAVAGE, K. E. Adsorption and mobility of metribuzin in soil. Weed Sci. v. 24, p. 525528, 1976.

SHAROM, M. S. \& STEPHENSON, G. R. Behavior and fate of metribuzin in eight Ontario soils. Weed Sci. v. 24, n. 2, p. 153160, 1976.

SHEA, P. J. Detoxification of herbicide residues in soil. Weed Sci. v. 33, supp. 2, p. 33-41, 1985.

SILVA, A. A. da. Eficiência do S-53482 no controle de plantas daninhas em cultura da soja. In: Congresso Brasileiro de Herbicidas e Plantas Daninhas, Londrina, 1993. Resumos... Londrina, SBHED, 1993. p. 8990.

VELINI, E. D. Comportamento de herbicidas no solo. In: SIMPÓSIO SOBRE MANEJO INTEGRADO DE PLANTAS DANINHAS EM HORTALIÇAS. BOTUCATU. 1992. Anais ... Botucatu, UNESP, 1992. p.44-64.

WAX, L. M. Incorporation depth and rainfall on weed control in soybeans with metribuzin. Agron. J. v. 69, p. 107-110, 1977. 